\title{
Sei whale movements and behaviour in the North Atlantic inferred from satellite telemetry
}

\author{
Rui Prieto $^{1, *}$, Mónica A. Silva ${ }^{1,2}$, Gordon T. Waring ${ }^{3}$, João M. A. Gonçalves ${ }^{1}$ \\ ${ }^{1}$ Departamento de Oceanografia e Pescas, IMAR and LARSyS Associated Laboratory, Universidade dos Açores, \\ 9901-862 Horta, Portugal \\ ${ }^{2}$ Biology Department, Woods Hole Oceanographic Institution, Woods Hole, Massachusetts 02543-1049, USA \\ ${ }^{3}$ NOAA Fisheries, Northeast Fisheries Science Center, 166 Water Street, Woods Hole, Massachusetts 02543-1026, USA
}

\begin{abstract}
The stock structure of the sei whale Balaenoptera borealis in the North Atlantic is unknown, despite years of commercial hunting. New and up-to-date data on distribution and movements are essential for the creation of plausible hypotheses about the stock structure of this species. Between 2008 and 2009 satellite tracks of 8 sei whales were obtained, 7 during spring and 1 in late September. Using a hierarchical switching state-space model we investigated the movements, behaviour and the role of distinct areas in their life history. Two distinct phases corresponding to migratory and foraging movements were identified. A migratory corridor between the Azores and the Labrador Sea is clearly identifiable from the data. Behaviour consistent with foraging was observed frequently in the Labrador Sea, showing that it constitutes an important feeding ground. A link between the Labrador Sea and other feeding grounds to the east is deemed likely. The data also support a discrete feeding ground in the Gulf of Maine and off Nova Scotia. A possible link between the feeding grounds in the Labrador Sea and wintering grounds off northwestern Africa is proposed.
\end{abstract}

KEY WORDS: Migration - Satellite tracking $\cdot$ Marine mammal $\cdot$ Stock structure $\cdot$ Labrador Sea Azores $\cdot$ Whale ecology $\cdot$ Sei whale

\section{INTRODUCTION}

The sei whale Balaenoptera borealis can be found in all oceans, predominantly in deep waters or near the continental slopes of temperate to subpolar waters. The species was heavily hunted worldwide, especially in the North Pacific and Southern Ocean (Horwood 1987), leading to a drastic population decline (Reilly et al. 2008).

In the North Atlantic nearly 17000 sei whales were killed in the period between 1885 and 1986 (Prieto et al. 2012). In 1982 the International Whaling Commission (IWC) adopted a moratorium on commercial whaling that came into effect in 1986 (Gambell 1993). Since that date fewer than 100 sei whales have been

\footnotetext{
*Corresponding author: rprieto@uac.pt
}

taken in the North Atlantic, all of them under scientific and aboriginal subsistence permits (Prieto et al. 2012).

Currently there are no abundance estimates for the entire sei whale population in the North Atlantic. Existing estimates from restricted areas indicate that the present population in the North Atlantic may be over 10000 animals (Prieto et al. 2012).

After the introduction of the moratorium on commercial whaling, the Scientific Committee of the IWC developed a new robust management procedure, coupling politically set management goals with the scientific aspects of management (Punt \& Donovan 2007, Cooke et al. 2012). This management procedure is called the 'revised management procedure' in

() Prieto, Silva and Gonçalves 2014. Open Access under Creative Commons by Attribution Licence. Use, distribution and reproduction are unrestricted. Authors and original publication must be credited. Publisher: Inter-Research · www.int-res.com 
IWC jargon, but is also known as 'management strategy evaluation' in other wildlife management applications (Smith et al. 1999, Milner-Gulland et al. 2010).

One of the primary features of the revised management procedure is that it explicitly takes into account uncertainty from several sources (Punt \& Donovan 2007). Performance of a management strategy in the face of uncertainties is evaluated through simulation trials considering, e.g. plausible alternative hypotheses about the underlying resource dynamics (Punt \& Donovan 2007, Milner-Gulland et al. 2010). A considerable part of that uncertainty may reside in issues of stock structure and the temporal and spatial variation in the mixing of stocks in the areas being evaluated (Punt \& Donovan 2007).

Thus, application of the revised management procedure depends on identifying a set of plausible alternative hypotheses of stock structure and on a good understanding of the patterns of migration, dispersal and mixing of animals from different breeding stocks on the feeding grounds.

Recently, the Scientific Committee of the IWC started to review the data for North Atlantic sei whales to determine whether sufficient data are available for application of the revised management procedure (Anonymous 2014).

Evidence for biological stocks or sub-stocks (sensu Jackson \& Pampoulie 2012) of sei whales in the North Atlantic is feeble (Donovan 1991). It has been hypothesized that 2 stocks occurred simultaneously in the summer in the Canadian Atlantic, termed the 'Labrador stock' and the 'Nova Scotia stock' (Mitchell \& Chapman 1977). Sei whales from the eastern North Atlantic were considered to belong to another stock (Donovan 1991). A link between the whales from the 'Labrador stock' and the Denmark Strait was held to be unlikely but possible by Mitchell \& Chapman (1977); however it is not clear if they thought the whales could belong to the same biological stock. Schmidly (1981) suggested that whales belonging to that purported stock were limited to waters around Newfoundland and Labrador and also suggested that another stock could exist in the Caribbean/Gulf of Mexico, but no supporting evidence was provided for either of those theories.

To address management needs, 3 management units were adopted by the IWC for the North Atlantic sei whale in 1977 (Fig. 1). The boundaries of those management units were apparently designed to accommodate existing whaling operations and to match boundaries of ICES fishing areas rather than trying to reflect actual population structure (Donovan
1991). Following the adoption of those boundaries the discussion about the stock structure of the North Atlantic sei whale within the IWC ceased, despite recognition that the issue was not settled (Donovan 1991).

Data on migration behaviour are also deficient. Existing theories suggest that migration on a north-south axis, on both sides the ocean basin. In the western North Atlantic, Mitchell \& Chapman (1977) suggested that whales belonging to the purported 'Nova Scotia stock' migrate along the North American shelf-break from and to unidentified wintering grounds at lower latitudes. Ingebrigtsen (1929) suggested that sei whales in the eastern North Atlantic migrated between wintering grounds somewhere off northwestern Africa and feeding grounds around Iceland and Scotland and in the Norwegian Sea. To the best of our knowledge, there is no migration theory for the purported 'Labrador stock'. Olsen et al. (2009) presented data on 1 sei whale equipped with a satellite tag off the Azores islands that moved to the Labrador Sea, showing for the first time that North Atlantic sei whales are capable of cross-ocean movements.

In 2008 and 2009, we equipped sei whales with satellite tags off the Azores islands with the goal of investigating (1) medium- to large-scale movements, (2) migratory routes and migratory destinations and (3) habitat use. We used a Bayesian hierarchical switching state-space model (hSSSM) (Block et al. 2011, Jonsen et al. 2013) to model surface positions and estimate movement parameters in order to infer migratory and foraging behaviours within whale tracks. The results of this study are reported here.

\section{MATERIALS AND METHODS}

\section{Data collection}

Satellite-monitored platform transmitter terminals (PTT) housed in surgical grade stainless steel (Model SPOT5-implantable; Wildlife Computers) were implanted in 16 sei whales off Faial and Pico Islands, in the Azores archipelago, Portugal ( $38^{\circ} \mathrm{N}, 28^{\circ} \mathrm{W}$; Fig. 1). Whales were tagged from May to June in 2008 and 2009 , except for 1 whale that was tagged in late September 2009 (Table 1). Tagging procedures were similar to those described in Olsen et al. (2009) and Silva et al. (2013). Tags were deployed from a $12 \mathrm{~m}$ fiberglass boat using a compressed air gun (Model ARTS/RN; Restech), similar to that described in Heide-Jørgensen et al. (2001), and set at 10 to 13 bar pressure. All tags were cleaned with $70 \%$ ethanol to 

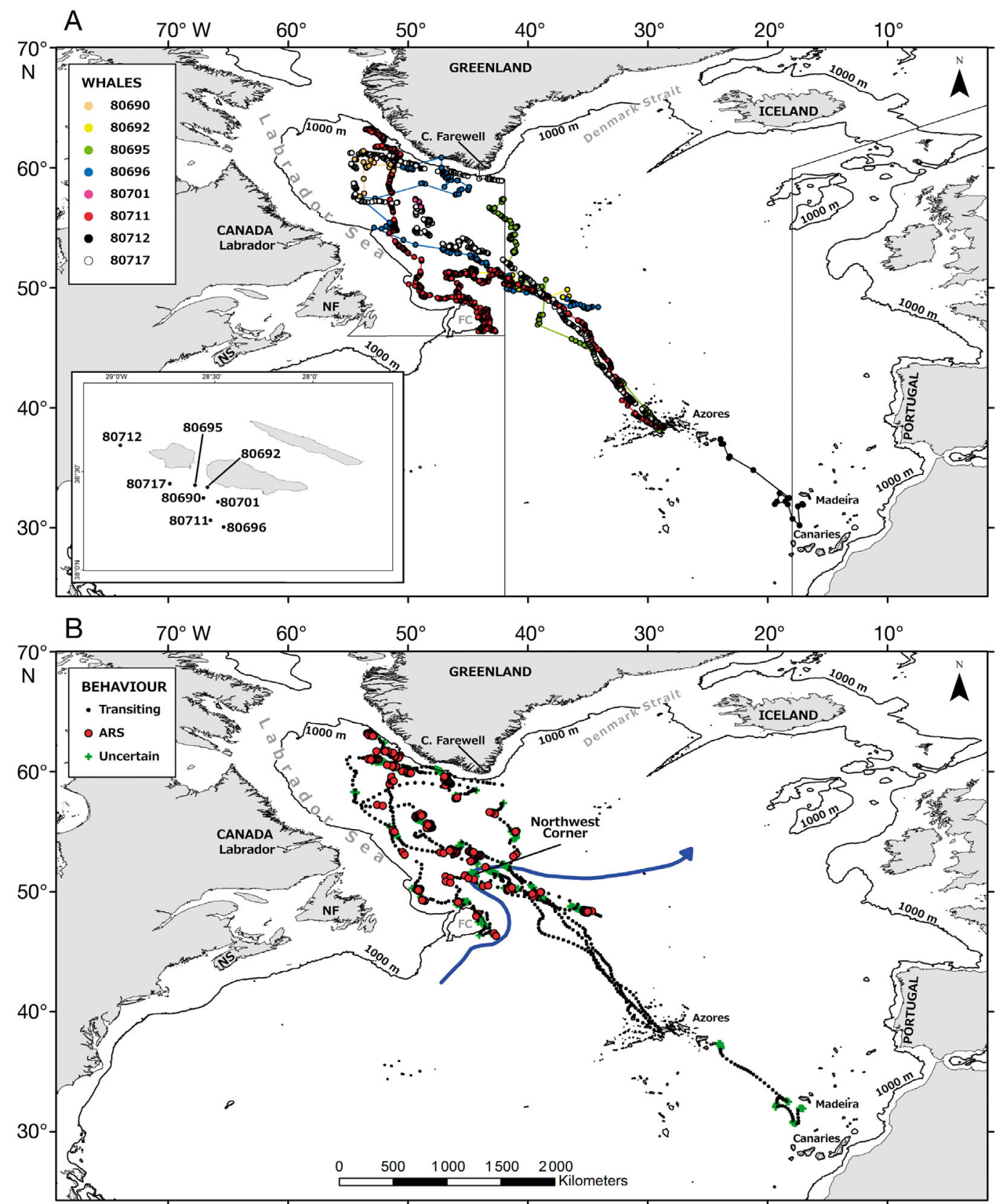

Fig. 1. Balaenoptera borealis. (A) Sei whale tracks derived from raw ARGOS locations. Tagging locations in the Azores are shown in the inset. International Whaling Commission stock boundaries for the species in the North Atlantic are shown as narrow lines. (B) Hierarchical switching state-space model-derived locations of sei whales showing inferred behavioural modes. The thick, blue line is a schematic representation of the main branch of the North Atlantic Current, showing the quasi-stationary large meander known as the 'Northwest Corner' and referred to in the text. ARS: area-restricted search; NS: Nova Scotia; NF: Newfoundland; FC: Flemish Cap

remove contaminants from manufacture and handling and then sterilized under UV light and stored in sterilized sealed bags until use. Prior to implantation, the tip was covered with gentamicin sulphate cream to act both as antibiotic and lubricant. Tags were attached to the back of the individuals, anterior to the dorsal fin, with a 4-bladed tip and held in place with 4 sets of barbs and 6 backward-facing petals.
In 2008 the tags were programmed to transmit every hour of the day, every other day, in an effort to prolong battery life. In 2009 no duty cycle was applied to the tags, since the experience gained in the previous year demonstrated that battery duration was not critical for deployment longevity. All tags were programmed to transmit a maximum of 500 messages $\mathrm{d}^{-1}$. 


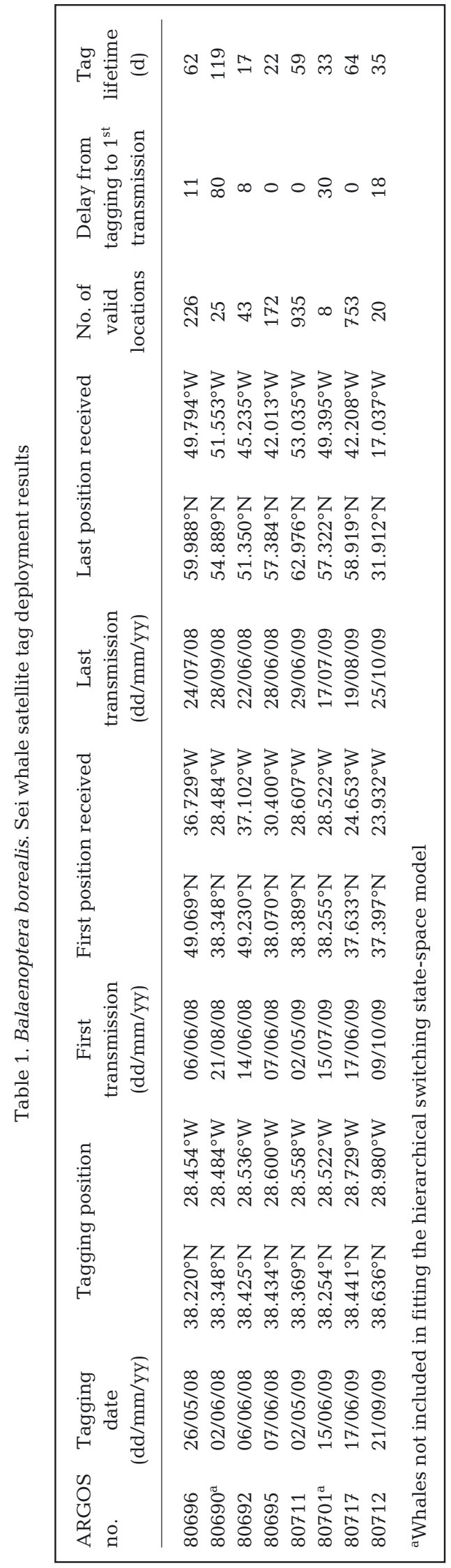

All procedures followed the guidelines of the American Society of Mammalogists (Gannon et al. 2007). Fieldwork and tagging were developed under research permits by the administrative authorities of the Autonomous Region of the Azores.

\section{Switching state-space model}

In order to analyse the movements and behaviour of tagged whales, we adopted a model-based stochastic approach by fitting a Bayesian switching state-space model (SSSM; Jonsen et al. 2005, 2013) to ARGOS-derived locations processed with the Kalman filter (Lopez et al. 2014). We chose to use the locations processed with the Kalman filter over those processed with the classical nonlinear least square algorithm (Lopez et al. 2014), since Silva et al. (2014) showed that state-space models fit better to locations processed with the Kalman filter.

The SSSM allows for simultaneous correction of location errors and estimation of a behavioural state. In order to accomplish this, the SSSM couples 2 models. The first is a process model (a first difference correlated random walk) that predicts the future state of an individual given its current state, based on the previous state of the data. The process model is complemented by an observation model of the time series data that relates the unobserved location states predicted by the process model to the observed positional data.

In heterogeneous landscapes it is assumed that predators will change their movement path in response to prey density, increasing their turning rates to stay within the prey patch, a behaviour that is often referred to as area-restricted search (ARS; Tinbergen et al. 1967, Kareiva \& Odell 1987). The SSSM allows indexing the movement parameters by behavioural states through the inclusion of a process model for each behavioural state (Jonsen et al. 2005). By assuming that the correlated random walk describing 2 distinct behavioural states (transiting or ARS) differs only in its values of mean turning angle and move persistence (autocorrelation in speed and direction), the SSSM can model switches between those states by calculating the probability of these changes through a Markov chain model (see Jonsen et al. 2013 for further background details).

In this study we fitted the SSSM as a single hierarchical model (hSSSM) to the combined data of several individuals (Jonsen et al. 2013). By using a hSSSM, information from all individuals can be pooled to more efficiently estimate parameters at 
both the individual and population levels (Gelman et al. 2003). In this hierarchical framework, the movement process for each individual whale $k$ is modelled by:

$$
\boldsymbol{d}_{t, k} \sim N_{2}\left[\gamma_{b t, k} \mathbf{T}\left(\theta_{b t, k}\right) \boldsymbol{d}_{t-1, k}, \Sigma\right]
$$

where $\boldsymbol{d}_{t^{-1}, k}$ is the displacement of whale $k$ between unobserved locations $x_{t-1}$ and $x_{t-2}$, and $\boldsymbol{d}_{t, k}$ is the displacement of whale $k$ between unobserved locations $x_{t}$ and $x_{t-1} . \mathbf{T}(\theta)$ is a behaviour-specific transition matrix describing the mean turning angle $(\theta)$ necessary to move from $\boldsymbol{d}_{t-1}$ to $\boldsymbol{d}_{t}, \gamma$ is the move persistence parameter and $N_{2}$ is a bivariate Gaussian random variable describing the stochasticity of the movement process with covariance matrix $\Sigma_{;}$the subscript $b t$ denotes the behavioural state. At each displacement $t$, the behavioural state $b$ takes a value corresponding to the set of parameters $\theta$ and $\gamma$ providing the best model fit.

The same priors on movement parameters as in Jonsen et al. (2013) were used, under the assumption that transit behaviour is characterized by turning angles close to $0^{\circ}$ and a higher autocorrelation in speed and direction than during ARS behaviour. This assumption is rooted in behavioural studies (e.g. Watkins \& Schevill 1979, Mayo \& Marx 1990) and has been broadly utilised in similar studies (e.g. Bailey et al. 2009, Silva et al. 2013, Kennedy et al. 2014).

The hSSSM was fitted using a time step of $4 \mathrm{~h}$, a value that comprises $90 \%$ of the transmission intervals recorded in the raw data (Fig. A1 in the Appendix). Models were fit using $\mathrm{R}$ ( $\mathrm{R}$ Development Core Team 2008) code provided by Jonsen et al. (2013). The code implements the hSSSM using Markov Chain Monte Carlo (MCMC) methods via the program JAGS. For each hSSSM we ran 2 MCMC chains for 50000 iterations, dropping the first 45000 samples as a burn-in and retaining every 5th sample from the remaining 5000 assumed post-convergence samples to reduce sample autocorrelation. Thus, model parameters and estimates of whales' locations and behaviours were calculated using a total of 2000 MCMC samples. Model convergence and sample autocorrelation were assessed by visually inspecting trace and autocorrelation plots and using the Gelman and Rubin diagnostic available in the R package 'boa'.

\section{Whale track analysis}

Whale behaviour at each modelled location was inferred from the output of the hSSSM. Although only 2 modes are modelled by the hSSSM, the means of the MCMC are presented as continuous values between 1 and 2 . We used the same cut-off values as Jonsen et al. (2007) and assumed that a mean behavioural mode $b<1.25$ represented transiting behaviour and a value of $b>1.75$ represented ARS. Any locations with mean behavioural modes between 1.25 and 1.75 were considered uncertain. These cutoff values are considered conservative and were used to ensure good distinction between the 2 behaviours (Jonsen et al. 2007).

Due to the lack of real time confirmation, it is impossible to be sure that all ARS classifications translate into active foraging. Nevertheless, it is well established that ARS generally corresponds to foraging in marine predators (Mayo \& Marx 1990, Fauchald 2009, Hamer et al. 2009, Papastamatiou et al. 2012). Another possibility is that ARS indicates resting or breeding behaviours (Bailey et al. 2009). However, since all but one animal were tagged during the known feeding season, it is unlikely that breeding behaviour was captured in the data. Thus, in the present work, we considered that ARS was predominantly indicative of foraging for all animals tagged during their northbound migration. In the context of this study, ARS will hereafter be referred to as 'foraging' for all northbound whales.

Based on data on travel direction and speed collected during fieldwork we assumed that all individuals were on migration when they were tagged. The migratory phase was assumed to have ceased when 3 or more consecutive locations within a track with a behavioural mode $b \geq 1.25$ were encountered. Foraging bouts were defined as 3 or more consecutive locations with a behavioural mode of $b>1.75$ (Bailey et al. 2009).

Movement parameters and statistics were calculated in R software using the packages 'geosphere' and 'circular'. Means are presented with \pm 1 standard deviation (SD).

\section{RESULTS}

Satellite tags were deployed on 8 sei whales in 2008 and on 6 in 2009, but data were received from only 4 whales in each year. Deployment data for working tags are summarized in Table 1.

ARGOS position estimates are assigned a level of accuracy within 7 classes: 3, 2, 1, 0, A, B and Z. Locations are tagged as Class $\mathrm{Z}$ when the algorithm fails to converge (Lopez et al. 2014) and for the purposes of our study were considered invalid. Locations in all 
other classes were considered valid and used in the analysis. A mean of $273( \pm 364)$ locations was received from each tag. Mean tag lifetime (from implantation to last transmission received) was $51.4 \mathrm{~d}$ $( \pm 32.9)$, and valid locations were received for a mean period of $31.0 \mathrm{~d}( \pm 23.2)$. Reception of the first transmission from the working tags had a mean delay of $18.4 \mathrm{~d}( \pm 27.0)$ in 5 of the tagged whales, rendering incomplete tracks for those individuals. All individuals but one (80712) were tagged between May and June, during the migration to higher latitudes. Hereafter we refer to these as northbound individuals. Individual 80712 was tagged in late September, presumably during the migration to wintering grounds. All individuals tagged during the spring and early summer moved to the Labrador Sea, and the signal of the whale tagged in September was lost in the region between the Madeira and Canary archipelagos (Fig. 1A).

The data from 2 individuals were not included when fitting the hSSSM: Individual 80701 due to the small number of valid locations $(\mathrm{n}=8)$ and Individual 80690 because the data included several large temporal gaps, resulting in a mean transmission interval of $37.2 \mathrm{~h}$ $( \pm 48.6)$, with a maximum interval of $182 \mathrm{~h}$.

In general there was good distinction between 2 behavioural modes, as indicated by the parameter estimates that aggregated in 2 non-overlapping groups (Fig. 2). Transiting comprised most of the 1292 locations inferred by the hSSSM (43\% of locations), with foraging accounting for $29 \%$ of those locations and $28 \%$ of locations remaining as uncertain. No ARS behaviour was detected for Individual 80712, although some behavioural estimates were classified as uncertain (Fig. 1B). For the northbound individuals, foraging was only detected north of $48^{\circ} \mathrm{N}$ and west of $34^{\circ} \mathrm{W}$. In total, 27 foraging bouts were identified, lasting from 8 to $132 \mathrm{~h}$ (mean \pm SD: $48.3 \pm 39 \mathrm{~h}$ ). Eventually all individuals crossed the North Atlantic Current into the Labrador Sea basin where $63 \%$ of the foraging bouts were detected (Fig. 1). At least 5 of the individuals crossed the North Atlantic Current between 51 and $53^{\circ} \mathrm{N}$ in the vicinity of a quasi-stationary large meander of that current known as the 'Northwest Corner', positioned at $\sim 51^{\circ} \mathrm{N}, 44^{\circ} \mathrm{W}$, just outside the $4000 \mathrm{~m}$ isobath (Fig. 1B; Worthington 1976, Lazier 1994, Belkin \& Levitus 1996).

Comparison of movement parameters on- and offmigration was conducted only for the individuals with complete tracks $(80695,80711,80712$ and 80717). Movement directionality was calculated separately

Table 2. Balaenoptera borealis. Sei whale movement parameters during migration and off-migration. Direction of travel refers to direction during transiting. See text for an explanation of northbound and southbound. Means are $\pm 1 \mathrm{SD}$

\begin{tabular}{|lcc|}
\hline & Migratory phase & Off-migration phase \\
\hline Mean transiting speed $\left(\mathrm{km} \mathrm{h}^{-1}\right)$ & $7.4 \pm 0.4$ & $6.2 \pm 0.8$ \\
Direction of travel (northbound) & $328.8 \pm 21.3^{\circ}$ & $345.5 \pm 80.0^{\circ}$ \\
Direction of travel (southbound) & $134.1 \pm 14.8^{\circ}$ & $145.4 \pm 102.2^{\circ}$ \\
\hline
\end{tabular}

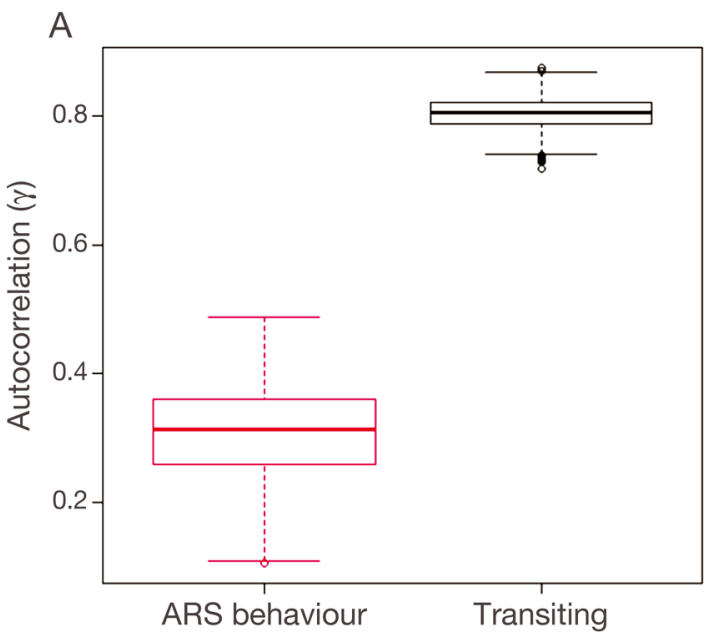

B Mean turning angle $(\theta)$

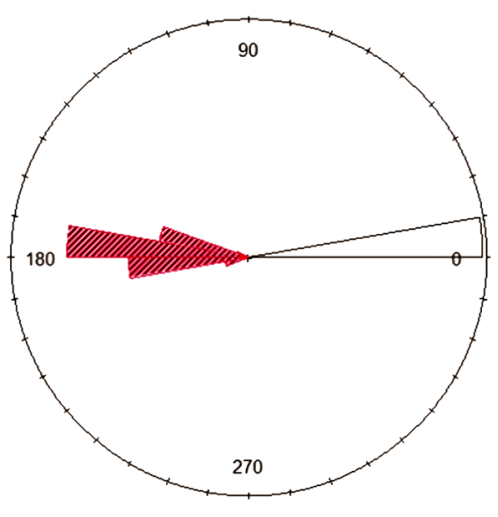

Fig. 2. Balaenoptera borealis. Distribution of movement parameters of sei whales in transiting (black) and area-restricted search (ARS; red). (A) Combined autocorrelation in speed and direction $(\gamma)$ : dark horizontal lines represent the median, with the box representing the 25th and 75th percentiles, the whiskers the 5th and 95th percentiles and outliers represented as dots.

(B) Mean turning angle $(\theta)$, based on the means from the Markov Chain Monte Carlo (MCMC) samples 


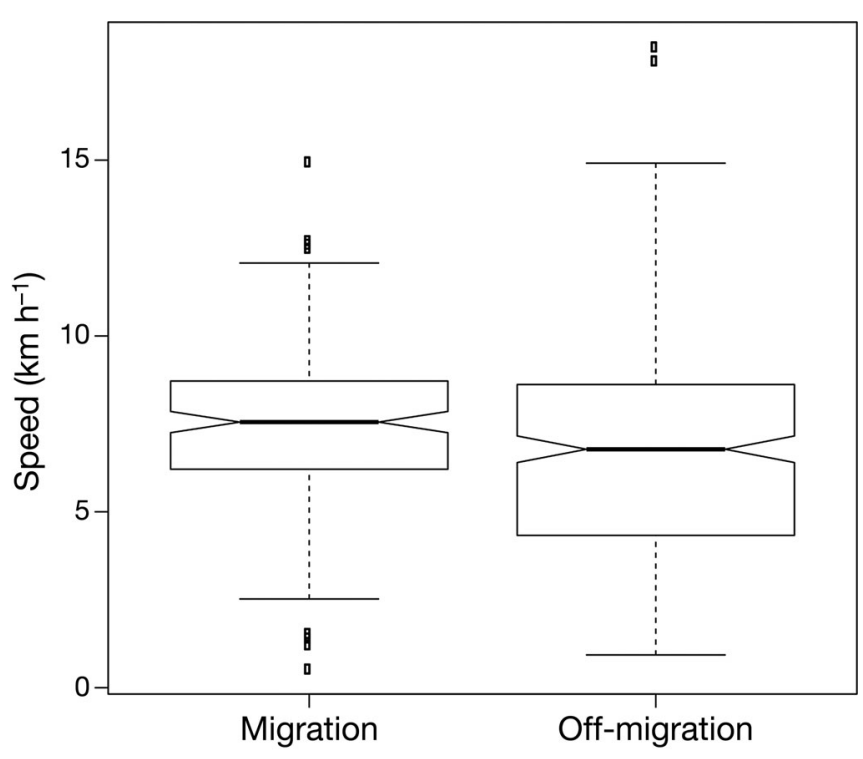

Fig. 3. Balaenoptera borealis. Notched boxplots of transit speeds of sei whales during migration and off-migration. Dark horizontal lines represent the median, with the box representing the 25th and 75th percentiles, the whiskers the 5th and 95th percentiles and outliers represented as small rectangles. The notch defines the $95 \%$ confidence interval on the median

for whales tagged in late spring and early summer (northbound) and for the whale tagged in late summer (southbound). Transit speeds were similar between the migration and off-migration phases (Fig. 3, Table 2). In contrast, and as expected, the movement directionality was considerably higher during migration (Fig. 4, Table 2).

\section{DISCUSSION AND CONCLUSIONS}

\section{Behavioural phases}

Our results clearly show 2 distinct phases in the tracking data of northbound individuals with uninterrupted tracks. Before the occurrence of state estimates with values $b \geq 1.25$ in northbound individuals, whales kept a nearly constant travel orientation, consistent within and among individuals. This type of persistent, straightened-out movement is characteristic of migration (Dingle 1996). Once state estimates with values $b \geq 1.25$ occurred, overall movement directionality decreased and travel direction among individuals ceased to be similar. Even when on transit, whales showed frequent changes of travel direction, and transiting behaviour was often interrupted by foraging bouts (Fig. 1), indicating that animals were no longer migrating (Dingle 1996).

These results indicate a well-defined migratory corridor between the Azores and the Labrador Sea. Whales tagged on completely different occasions followed very similar tracks, ending their migration in a relatively restricted area. Those results are further backed by Olsen et al. (2009), who report on a sei whale tagged in the Azores in April 2005 that also moved to the Labrador Sea.

Interpretation of the data from Individual 80712 is more problematic. The directional movement between the Azores and Madeira is also consistent with migratory behaviour. Between Madeira and the Canaries the animal changed travel direction several times, and, although no ARS was detected, some
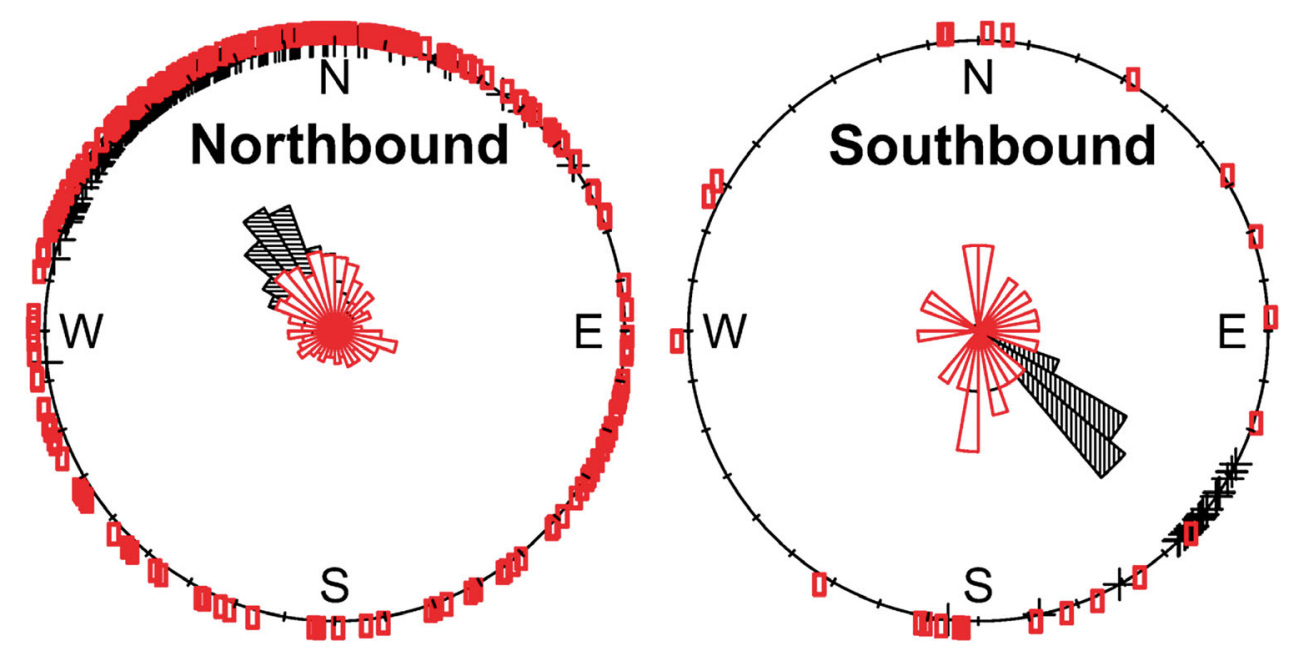

Fig. 4. Balaenoptera borealis. Distribution of direction of travel of sei whales during migration and off-migration. Crosses and hatched bins correspond, respectively, to data values and frequencies of travel direction during migration. Squares and hollow bins refer to off-migration travel direction. Area of bins is proportional to the group frequency. See text for an explanation of northbound and southbound 
modelled locations were classified as uncertain. Given that these data are from a single individual, trying to interpret this apparent change in behaviour would be highly speculative, and we thus refrain from doing so.

Locations with behavioural state values $b>1.75$, interpreted as foraging, were only detected north of $48^{\circ} \mathrm{N}$, in the vicinity of a well-known oceanographic feature (the Northwest Corner). The Northwest Corner is characterised by the interaction of warm waters from the North Atlantic Current with colder waters from the Labrador Sea (Worthington 1976, Lazier 1994, Belkin \& Levitus 1996). It has been hypothesised that whales can use ocean current patterns and water mass characteristics as directional cues or 'guideposts' (Kenney et al. 2001). The sudden change in the flow characteristics of the current at the vicinity of the Northwest Corner, in combination with the drastic temperature and salinity variations, may serve as cues that trigger the initiation of foraging behaviour.

\section{Role of the Labrador Sea as a feeding ground and its relation to other known feeding grounds}

It is believed that the large migratory movements of baleen whales from calving/breeding to feeding grounds is related to their requirement of large quantities of high-energy prey found only in highly productive cold waters (Stern 2009). In the North Atlantic, sei whales feed primarily on the copepod Calanus finmarchicus, and it is expected that they will favour areas with high concentrations of that prey as preferred feeding grounds (Prieto et al. 2012).

In the past, the Labrador Sea was among the known feeding grounds used by sei whales in the North Atlantic (Mitchell \& Kozicki 1974). However, since the early 1970s information on sei whale presence and ecology in that region is virtually non-existent. Sei whales disappeared from or became rare in other known feeding grounds in the northeastern North Atlantic where they were once common (Prieto et al. 2012), but such information was unavailable for the Labrador Sea.

Our data not only position sei whales in the Labrador Sea, but also show that they spend considerable time foraging while there. Most of the 27 ARS bouts detected occurred when whales were well within the Labrador Sea and lasted from 2 up to 5.5 d. At least 4 individuals eventually moved to the waters just south of the Greenland shelf, where $C$. finmarchicus dominates the mesozooplankton biomass in spring and early summer (Head et al. 2003, Frajka-Williams \& Rhines 2010). In light of that evidence it is reasonable to assume that the tagged whales moved to the Labrador Sea because that region still plays an important role in their feeding ecology.

As summer progresses, or in response to changing conditions, it is conceivable that some individuals move to other feeding grounds, leaving the Labrador Sea. High densities of sei whales have been reported in areas southeast of Cape Farewell, Greenland (Sigurjónsson et al. 1991, Waring et al. 2008). Based on data from summer sighting surveys undertaken southeast and east of Greenland, Sigurjónsson et al. (1991) suggested a movement of whales from areas located southwest of Greenland to the Denmark Strait.

Few of the satellite tags transmitted into late summer, resulting in an incomplete representation of the whales' movements during the feeding season. Nevertheless, 2 whales $(80695,80717)$ were apparently heading east of Cape Farewell when their signals were lost on June 28 and August 19, 2008, respectively. A link between sei whales in the Labrador Sea and in the Iceland-Denmark Strait cannot be indisputably established based solely on the data of the present study. However, we find that hypothesis compelling based on the available data.

One of the arguments used to suggest the existence of 2 sei whale stocks off the United States and Canadian east coasts was the simultaneous occurrence of this species in the Labrador Sea and off New England and Nova Scotia during spring and early summer (Mitchell \& Chapman 1977). A similar pattern emerged from our data. Tagged sei whales arrived in the Labrador Sea as early as mid-May, and some animals stayed in that area until at least mid-September. Sei whales are known to use the waters of the Gulf of Maine as a feeding ground between spring and early summer (Baumgartner et al. 2011). Thus, the Gulf of Maine and the Labrador Sea seem to comprise 2 discrete feeding grounds, utilized simultaneously by sei whales. Nevertheless, it is not possible from our data to speculate if whales frequenting those feeding grounds belong to distinct biological stocks or substocks (sensu Jackson \& Pampoulie 2012).

\section{Relation of sei whales seen in the Azores to purported wintering grounds}

It is not possible to know where the whales that were tagged in the Azores originated. However, it seems unlikely that whales originating from hypothesised wintering grounds located somewhere off the 
American coast would head to the Azores and then veer to the Labrador Sea, which would add thousands of kilometres to the journey. Unless the Azores constituted an important feeding station during migration, this detour would result in important additional energy expenditure to migrating individuals for no evident advantage. In the present study, no foraging behaviour was detected for sei whales in the vicinity of the Azores. Additionally, photo-identification and behavioural data suggest that sei whales have short residency times near the islands and seldom engage in foraging activities (R. P. and M. A. S. unpubl. data). In view of this, the most plausible hypothesis is that sei whales migrating through the Azores in spring/summer originate somewhere south or southeast of the archipelago.

The whale that was tagged in late September (80712) moved southeast and its signal was lost between the Madeira and Canary archipelagos. Ingebrigtsen (1929) was the first to allude to a sei whale wintering ground off northwestern Africa. Between 1976 and 1978 the unregulated catcher boat 'Sierra' captured $>100$ sei whales in a small area just north of the Cape Verde archipelago during winter and spring months (Best 1992), supporting the notion of a northwestern Africa wintering ground. More recently, the presence of sei whales in the same area during early spring was confirmed, offering further evidence for a wintering ground in the region (Prieto et al. 2012). It is likely that the whale tagged in late September was on its southbound migration towards wintering grounds located somewhere in that region. However, further work is needed to confirm this.

It is tempting to draw a line and conclude a link between the presumed wintering area off northwestern Africa and the Labrador Sea feeding ground. Although this seems to be a likely possibility, such an assumption may be flawed. In a scenario of multiple biological stocks, due to its position in the central North Atlantic, it is conceivable that the Azores is frequented by whales from one stock during the spring migration and from another during late summer and autumn.

\section{Concluding remarks}

There are still great gaps in our understanding of the distribution, movements and population structure of the sei whale in the North Atlantic (Donovan 1991, Prieto et al. 2012). The results reported in the present study shed some light on the movements and behaviour of sei whales that migrate through the Azores. From our results, it is possible to dismiss at least one theory about stock structure; the data indisputably show that sei whales in the Labrador Sea are not isolated as proposed by Schmidly (1981).

Understanding the implications of overlap and mixing of biological stocks in feeding grounds is a major consideration for the management of whaling activities (Hoelzel 1998, Punt \& Donovan 2007). Our data indicate, although not indisputably, that sei whales using the Labrador Sea feeding ground may also use other known feeding grounds to the east. Additionally, prior to going to the Labrador Sea the whale that was tracked in the study by Olsen et al. (2009) visited the Charlie Gibbs Fracture Zone, at a longitude of $\sim 30^{\circ} \mathrm{W}$, where large aggregations of feeding sei whales have been reported (Waring et al. 2008). The combined results reported by Olsen et al. (2009) and in this study give some support for the idea of a continuum of the feeding grounds located in the Labrador Sea with other feeding grounds located southeast and east of Greenland, up to the Denmark Strait, as suggested by Sigurjónsson et al. (1991). Whether this results in mixing of different stocks remains to be investigated.

Our data also support the idea of a discrete feeding ground located off the Gulf of Maine and Nova Scotia. Investigating if there is any degree of genetic differentiation between animals utilising that feeding ground and other known feeding grounds such as the Labrador Sea and the Irminger Sea (southwest of Iceland) should be a priority.

The telemetry data show a clear migratory corridor for sei whales between the Azores and the Labrador Sea. This result is not only relevant for management within the IWC. Injury and mortality resulting from ship strikes represent a major conservation problem for many cetacean species (Moore 2014). Information on the geographical and temporal distribution of migration corridors is essential to reduce ship strikes (Mullen et al. 2013).

Our study shows that satellite telemetry can be a powerful tool to study data-poor species such as the sei whale and contributes to the creation of plausible hypotheses about population structuring. In that respect, it is important to continue and expand studies on the movement and migration of the sei whale in the North Atlantic in order to better understand the distribution and isolation of breeding and feeding grounds, as well as to clearly identify migratory routes and aggregation areas. However, despite the tremendous potential of satellite telemetry, this technique is limited if not combined with other lines of inquiry. In the case of North Atlantic sei whales, investigating the genetic structuring within the ocean basin is essential. 
Acknowledgements. We are grateful to the skippers, crew members, students and volunteers that helped with fieldwork. Special thanks are owed to Irma Cascão, Maria João Cruz, Cláudia Oliveira, João Medeiros and Yves Cuenot for their assistance during fieldwork. We acknowledge the collaboration of the whale-watching operators and 'vigias' of Faial and Pico. This research was supported by Fundação para a Ciência e Tecnologia (FCT), Fundo Regional da Ciência, Tecnologia (FRCT), through research projects TRACEPTDC/MAR/74071/2006 and MAPCET-M2.1.2/F/012/2011 (FEDER, the Competitiveness Factors Operational [COMPETE], QREN European Social Fund, and Proconvergencia Açores/EU Program). We acknowledge funds provided by FCT to LARSyS Associated Laboratory \& IMAR - University of the Azores/the Thematic Area D \& E of the Strategic Project PEst-OE/EEI/LA0009/2011-1012 and 2013-2014 (OE \& Compete) and by the FRCT-Government of the Azores pluriannual funding. M.A.S. was supported by $\mathrm{POPH}$, QREN European Social Fund and the Portuguese Ministry for Science and Education, through an FCT Investigator grant. R.P. was supported by an FCT doctoral grant (SFRH/ BD/41192/2007) and by a research grant from the Azores Regional Fund for Science and Technology (M3.1.5/F/115/ 2012). Lastly, we acknowledge Dr. Phil Clapham and an anonymous reviewer whose comments on a prior version of this manuscript greatly improved it.

\section{LITERATURE CITED}

Anonymous (2014) Report of the scientific committee. J Cetacean Res Manag 15 (Suppl):1-75

Bailey H, Mate BR, Palacios DM, Irvine L, Bograd SJ, Costa DP (2009) Behavioural estimation of blue whale movements in the Northeast Pacific from state-space model analysis of satellite tracks. Endang Species Res 10:93-106

Baumgartner MF, Lysiak NSJ, Schuman C, Urban-Rich J, Wenzel FW (2011) Diel vertical migration behavior of Calanus finmarchicus and its influence on right and sei whale occurrence. Mar Ecol Prog Ser 423:167-184

> Belkin IM, Levitus S (1996) Temporal variability of the Subarctic Front near the Charlie-Gibbs Fracture Zone. J Geophys Res 101:28317-28324, doi:10.1029/96JC02794

Best PB (1992) Catches of fin whales in the North Atlantic by the M.V. Sierra (and associated vessels). Rep Int Whal Comm 42:697-700

Block BA, Jonsen ID, Jorgensen SJ, Winship AJ and others (2011) Tracking apex marine predator movements in a dynamic ocean. Nature 475:86-90

Cooke J, Leaper R, Wade P, Lavigne D, Taylor BL (2012) Management rules for marine mammal populations: a response to Lonergan. Mar Policy 36:389-392

Dingle H (1996) Migration: the biology of life on the move. Oxford University Press, New York, NY

Donovan GP (1991) A review of IWC stock boundaries. Rep Int Whal Comm Spec Issue 13:39-68

Fauchald P (2009) Spatial interaction between seabirds and prey: review and synthesis. Mar Ecol Prog Ser 391:139-151

Frajka-Williams E, Rhines PB (2010) Physical controls and interannual variability of the Labrador Sea spring phytoplankton bloom in distinct regions. Deep-Sea Res I 57: 541-552

Gambell R (1993) International management of whales and whaling: an historical review of the regulation of commercial and aboriginal subsistence whaling. Arctic 46:97-107
Gannon WL, Sikes RS and the The Animal Care and Use Committee of the American Society of Mammalogists (2007) Guidelines of the American Society of Mammalogists for the use of wild mammals in research. J Mammal 88:809-823

Gelman A, Carlin JB, Stern HS, Rubin DB (2003) Bayesian data analysis. CRC Press, Boca Raton, FL

> Hamer KC, Humphreys EM, Magalhães MC, Garthe S and others (2009) Fine-scale foraging behaviour of a mediumranging marine predator. J Anim Ecol 78:880-889

- Head EJH, Harris LR, Yashayaev I (2003) Distributions of Calanus spp. and other mesozooplankton in the Labrador Sea in relation to hydrography in spring and summer (1995-2000). Prog Oceanogr 59:1-30

Heide-Jørgensen MP, Kleivane L, Øien N, Laidre KL, Jensen MV (2001) A new technique for deploying satellite transmitters on baleen whales: tracking a blue whale (Balaenoptera musculus) in the North Atlantic. Mar Mamm Sci 17:949-953

- Hoelzel AR (1998) Genetic structure of cetacean populations in sympatry, parapatry, and mixed assemblages: implications for conservation policy. J Hered 89:451-458

Horwood J (ed) (1987) The sei whale: population biology, ecology \& management. Croom Helm, London

Ingebrigtsen A (1929) Whales captured in the North Atlantic and other seas. Rapp P-V Reun Cons Int Explor Mer 56: $1-26$

Jackson JA, Pampoulie C (2012) Stock definition: terminologies revisited. Scientific Committee of the International Whaling Commission, Paper SC/64/SD3:1-4. http://iwc. int/document_2823.download

> Jonsen ID, Flemming JM, Myers RA (2005) Robust statespace modeling of animal movement data. Ecology 86 : 2874-2880

Jonsen ID, Myers RA, James MC (2007) Identifying leatherback turtle foraging behaviour from satellite telemetry using a switching state-space model. Mar Ecol Prog Ser 337:255-264

Jonsen ID, Basson M, Bestley S, Bravington MV and others (2013) State-space models for bio-loggers: a methodological road map. Deep-Sea Res II 88-89:34-46

> Kareiva P, Odell G (1987) Swarms of predators exhibit 'preytaxis' if individual predators use area-restricted search. Am Nat 130:233-270

> Kennedy AS, Zerbini AN, Rone BK, Clapham PJ (2014) Individual variation in movements of satellite-tracked humpback whales Megaptera novaeangliae in the eastern Aleutian Islands and Bering Sea. Endang Species Res 23: 187-195

Kenney RD, Mayo CA, Winn HE (2001) Migration and foraging strategies at varying spatial scales in western North Atlantic right whales: a review of hypotheses. J Cetacean Res Manag 2:251-260

Lazier J (1994) Observations in the Northwest Corner of the North Atlantic Current. J Phys Oceanogr 24:1449-1463

Lopez R, Malardé JP, Royer F, Gaspar P (2014) Improving Argos doppler location using multiple-model Kalman filtering. IEEE Trans Geosci Remote Sens 52:4744-4755

Mayo CA, Marx MK (1990) Surface foraging behaviour of the North Atlantic right whale, Eubalaena glacialis, and associated zooplankton characteristics. Can J Zool 68: 2214-2220

Milner-Gulland EJ, Arroyo B, Bellard C, Blanchard J and others (2010) New directions in management strategy evaluation through cross-fertilization between fisheries 
science and terrestrial conservation. Biol Lett 6:719-722 Mitchell ED, Chapman DG (1977) Preliminary assessment of stocks of northwest Atlantic sei whales (Balaenoptera borealis). Rep Int Whal Comm Spec Issue 1:117-120

Mitchell ED, Kozicki VM (1974) The sei whale (Balaenoptera borealis) in the northwest Atlantic Ocean. IWC doc SC/SP74/32. IWC, Cambridge. www.car-spaw-rac.org/ IMG/pdf/The_Sei_whale_Balaenoptera_borealis_in_the_ Northern_Atlantic_Ocean.pdf.

Moore MJ (2014) How we all kill whales. ICES J Mar Sci 71:760-763

Mullen KA, Peterson ML, Todd SK (2013) Has designating and protecting critical habitat had an impact on endangered North Atlantic right whale ship strike mortality? Mar Policy 42:293-304

Olsen E, Budgell P, Head E, Kleivane L and others (2009) First satellite-tracked long-distance movement of a sei whale (Balaenoptera borealis) in the North Atlantic. Aquat Mamm 35:313-318

Papastamatiou YP, DeSalles PA, McCauley DJ (2012) Arearestricted searching by manta rays and their response to spatial scale in lagoon habitats. Mar Ecol Prog Ser 456: 233-244

Prieto R, Janiger D, Silva MA, Waring GT, Gonçalves JM (2012) The forgotten whale: a bibliometric analysis and literature review of the North Atlantic sei whale Balaenoptera borealis. Mammal Rev 42:235-272

Punt AE, Donovan GP (2007) Developing management procedures that are robust to uncertainty: lessons from the International Whaling Commission. ICES J Mar Sci 64: 603-612

R Development Core Team (2008) R: A language and environment for statistical computing. R Foundation for Statistical Computing, Vienna. www.r-project.org

Reilly SB, Bannister JL, Best PB, Brown M and others (2008) Balaenoptera borealis. In: IUCN 2013 (ed) IUCN Red List of threatened species, Version 20132. www.iucnredlist.org (accessed 1 April 2014)

Schmidly DJ (1981) Marine mammals of the southeastern
United States coast and the Gulf of Mexico (FWS/OBS80/41). US Fish and Wildlife Service, Office of Biological Services, Washington, DC

Sigurjónsson J, Gunnlaugsson T, Ensor P, Newcomer MW, Vikingsson GA (1991) North Atlantic sightings survey 1989 (NASS-89): shipboard surveys in Icelandic and adjacent waters July-August 1989 (Balenoptera borealis, Balaenoptera physalus, Balaenoptera acutorostrata). Rep Int Whal Comm 41:559-572

Silva MA, Prieto R, Jonsen I, Baumgartner MF, Santos RS (2013) North Atlantic blue and fin whales suspend their spring migration to forage in middle latitudes: building up energy reserves for the journey? PLoS ONE 8: e76507

> Silva MA, Jonsen I, Russell DJF, Prieto R, Thompson D, Baumgartner MF (2014) Assessing performance of Bayesian state-space models fit to Argos satellite telemetry locations processed with Kalman filtering. PLoS ONE 9:e92277

Smith ADM, Sainsbury KJ, Stevens RA (1999) Implementing effective fisheries-management systems - management strategy evaluation and the Australian partnership approach. ICES J Mar Sci 56:967-979

Stern SJ (2009) Migration and movement patterns. In: Perrin WF, Würsig B, Thewissen JGM (eds) Encyclopedia of marine mammals. Academic Press, London

> Tinbergen N, Impekoven M, Franck D (1967) An experiment on spacing-out as a defence against predation. Behaviour 28:307-320

Waring GT, Nottestad L, Olsen E, Skov H, Vikingsson GA (2008) Distribution and density estimates of cetaceans along the mid-Atlantic Ridge during summer 2004. J Cetacean Res Manag 10:137-146

Watkins WA, Schevill WE (1979) Aerial observation of feeding behavior in four baleen whales: Eubalaena glacialis, Balaenoptera borealis, Megaptera novaeangliae, Balaenoptera physalus. J Mammal 60:155-163

Worthington LV (1976) On the North Atlantic circulation. The Johns Hopkins University Press, Baltimore, MD

Appendix. Fig. A1. Balaenoptera borealis. Transmission intervals of ARGOS-derived surface locations from the sei whales used in fitting the hierarchical switching state-space model

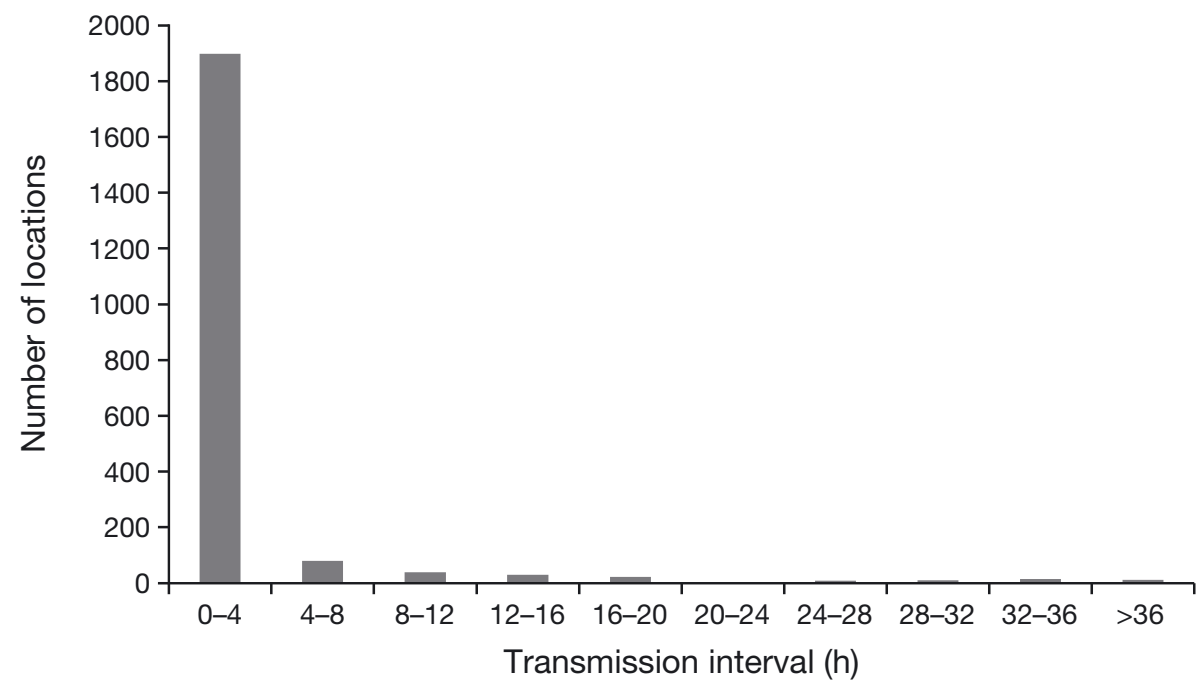

